\title{
The Parish Clergy as a Mental Health Resource
}

\section{NORMAN A. CLEMENS, RICHARD B. CORRADI, and MARVIN WASMAN}

In the search for community mental health resources, the clergy have been recognized as having a large existing role and great potential for further development. It has been reported that forty-two percent of people with mental or emotional problems turn first to their pastor to find help. ${ }^{1}$ Some community mental health specialists are aware of the extensive pastoral counseling done by clergy, their ready access to people's homes, their traditional roles at critical points in the life cycle, and the opportunity for utilizing many aspects of their ministry to promote community mental health principles. ${ }^{23}$ Yet the work of the clergy is ignored or misunderstood by a large proportion of mental health professionals. The purpose of this paper is to examine the role of the parish clergy from a mental health point of view and to discuss its strengths and weaknesses.

The following observations regarding the mental health role of the parish clergy have emerged from a program of continuing education in mental health for clergy that has been conducted in Cleveland since 1967 and is now known as the Pastoral Psychology Service-Institute. Over twenty percent of the clergy in the Cleveland area have participated in weekly two-and-a-half-hour smallgroup seminars with mental health professionals for up to four academic years, discussing the whole range of their professional activities with a particular emphasis upon pastoral counseling. Recruitment for our program is by mailings and other publicity reaching virtually all the clergy in the community. Thus, we see a self-selected cross-section of those clergy who are concerned enough about the mental health aspects of their pastoral work to enroll in the program. The teaching method is based upon presentation and examination of current pastoral experience, with use of additional instructional material when relevant and practical. It is the task of the group to integrate contributions from the mental health point of view with their role as ministers in a religious faith. The mode of instruction and an evaluation by independent observers will be presented in detail in another communication. ${ }^{4}$ Views of the

The authors are with the Department of Psychiatry, Case Western Reserve University School of Medicine, Cleveland, Ohio, where Norman A. Clemens, M.D., is Assistant Clinical Professor of Psychiatry, Richard B. Corradi, M.D., is Assistant Professor of Psychiatry, and Marvin Wasman, Ph.D., is Assistant Professor of Psychology.

The work described in this paper has been supported in part by National Institute of Mental Health grant no. MH-11929-01 and by grants from the Cleveland Foundation and the Grant Foundation, Inc., and the Cuyahoga County Board of Mental Health and Mental Retardation. 
clergy's role in mental health based on other experiences have been described by various authors. ${ }^{23,5-8}$ Partly on the basis of his experience as an instructor in our program, Rosen has explored the contribution of religion and the minister to mental and physical health. ${ }^{9}$ Clemens has reported on work with an advanced group in our program dealing with terminal illness and bereavement.10

\section{The clergy's role from a mental health viewpoint}

Whether he (or she) likes it or not, the clergyman (or woman) is a front-line worker in dealing with mental and emotional problems. However, he is primarily known to the community in his role as a religious leader and usually has had little, if any, formal training in pastoral counseling. People turn to their pastor for counseling because of his position in the parish and the community. He has an established, familiar, professional role with centuries of tradition behind him. He embodies values of receptivity and concern for individual human beings, their feelings, and their problems. The structure of the parish leads to an ongoing relationship with a large group of people, which invites comparisons to the service area of a community mental health center. The pastor's work takes him out into the community, where it is customary and accepted for him to visit homes, places of work, schools, and hospitals. Through his everyday contact with people he is in a position to intervene at a time when difficulties first arise. His schedule is flexible and he does not charge a fee.

Furthermore, his religious and sacramental functions bring him into contact with parishioners at critical points in life. Weddings, baptisms, confirmations, the confessional, sick calls, funerals-all relate to major developmental events or life crises. In addition to the religious observances, which frequently deal with emotional responses, a great deal of education and counseling takes place around these events, putting the pastor in a position to encourage healthy resolution of crises as well as emotional growth.

In the church or synagogue school the curriculum deals with the quality of living: e.g., the handling of common life stresses and the development of social controls, constructive self-expression, values, ideals, and conscience. In addition, it attempts to impart the meaning of history, tradition, and past experience with universal human problems, all of which have many implications for personality development. It affords contacts between the pastor and parents and the pastor and children in their formative years. Other educational and social groups within the church provide natural interaction with people who are sharing mutual experiences in all stages of the life cycle. The weekly sermon frequently deals with psychological issues such as anxiety, expression of feelings, conscience and control of drives, self-esteem and the love of others, facing reality, loss and adversity, and the fear of death. It is obvious that there is potential for harm as well as good in these parish functions. Ironically, these 
are the areas where the clergyman is best prepared to function constructively by his traditional background and yet is least cognizant of his potential effectiveness in terms of promoting mental health.

For some people who have nowhere else to turn, the church serves as a focal point for comfort, guidance, a sense of belonging, social involvement-in effect it serves as a family, a resemblance fostered by much religious symbolism. This includes some people who are vulnerable to emotional and mental difficulty and who may have exhausted all of the mental health resources available to them.

The tradition of pastoral counseling predates our modern knowledge of psychopathology. In the hands of mature, understanding clergy the pastoral relationship lends itself to effective supportive responses. It may support healthy functioning and allay anxiety through the promise of supernatural aids in meeting life challenges, or it may bolster controls by setting firm limits on what a person may or may not do. Such responses may serve to diminish the level of conflict within the personality and thus enhance the parishioner's sense of wholeness. Supportive counseling can be given in a manner so as to avoid encouraging passivity and dependency. In times of crisis, such as the death of a loved one, religious counseling offers an established way of behaving and of handling powerful feelings. The pastor's historical and philosophical perspective may provide a calming influence in a crisis, encouraging common sense and more considered judgment. Because of the pastor's ongoing knowledge of his parishioners, a great deal of effective counseling may occur in unobtrusive, informal contacts that are easily accepted by the parishioner, carry no stigma, permit the pastor to initiate interventions, and have a natural basis for following through.

We are impressed both by the sheer volume and also by the complexity of the counseling problems that congregants bring to their clergy. Often the problems involve acute and stressful life events such as illness and death. On the other hand, they frequently represent situations of chronic personal and family psychopathology that have smoldered for some time, have been poorly recognized by the participants, and have finally erupted in an event that takes on crisis proportions. These crises are then forced upon the pastor in a context of great urgency because those concerned are overwhelmed by conflicting feelings. Often in these circumstances the pastor is the object of inappropriate and unrealistic expectations, which he himself may share.

The clergy's unique position stimulates the whole gamut of "transference" and "countertransference" phenomena, in which the congregant or counselor may react inappropriately in a contemporary situation because of unconscious childhood conflicts. For the distraught congregant in a state of emotional crisis, the pastor, in the context of his religious mystique, can easily be unconsciously misperceived. Magical thinking and intensely ambivalent feelings may impair realistic problem solving. And yet the comfort and authority of religious responses, familiar through years of repetition, may have a powerfully supportive influence on the beleaguered individual. 


\section{Preparation, resources, and disadvantages}

How well prepared are the clergy to bear these extensive mental health responsibilities? Until recent years the seminary background in pastoral counseling had done little to integrate the knowledge and skills of the mental health disciplines with traditional religious responses. Available training frequently focused on medical or psychiatric patients rather than on congregants in their own life setting. The development of skills through ongoing individualized supervision or consultation was a rarity. Most of the clergy participating in our program had made a conscientious effort to read or to attend whatever seminars were available to broaden their knowledge. However, very few had had the opportunity to translate such didactic exercises into practical experience under skilled supervision.

Fortunately, in most of his ministering to his congregants' emotional needs the pastor faces realistic expectations, which he is well equipped to meet. When critical life events such as births, marriage, illness, and death call for compassion, sensitivity, and emotional support, he is usually prepared to meet these needs both by training and by virtue of his genuine concern for people. In situations where he encounters neurotic expectations, he has difficulty and is ill prepared by his conventional training. Our evaluation indicated that in these instances the pastor feels inadequate and overwhelmed. He often feels guilty about his inability to meet the congregants' demands for quick solutions to extremely complex problems.His theological training and human compassion compel him to act to relieve emotional suffering. It is then that he sometimes feels pressured to make an intervention based more on compassion than on knowledge; its ineffectiveness only adds to his guilt and frustration.

For the most part the clergy operate without knowledge of the theory and clinical procedure fundamental to the mental health disciplines. They have little background in child development, personality psychodynamics, or theories of crisis intervention. They know little about transference or defense mechanisms, personality strengths and weaknesses, or the manifestations of mental conflict. They tend to respond intuitively to these phenomena without recourse to the operational guidelines indispensable to the mental health professional. Their evaluation of counseling situations lacks an orderly approach based on the formation and testing of hypotheses, making it hard for them to know what information is relevant. They have difficulty proceeding in a sequential fashion through the phases of gathering information, forming conclusions as to the nature of the problem, structuring a counseling response, and carrying out a plan of intervention to its conclusion.

Although they can usually establish a warm, supportive relationship with congregants, they lack interviewing skills necessary to develop detailed histories or to get to the core of a congregant's concerns. On the other hand, many clergy are intuitively effective interviewers, and others improve significantly when given appropriate training. Under pressure of not knowing how to proceed, it is all too easy to fall back upon superficial responses: religious homilies, a text from the Bible, some words of positive thinking, and a prayer 
of dismissal. The parishioner may feel that the pastor has not grasped the problem and may seek help elsewhere if he is able. With sufficient understanding, however, the pastor may implement appropriate follow-through and short-term counseling measures. While the clergy are often quite knowledgeable about community resources, they can generally profit by a more organized orientation to service agencies and to techniques of referral.

In common with the other helping professions, the pastor must come to grips with his own reluctance to encourage the parishioner to express feelings. This hesitation may arise partly from a fear of taking on more than he can handle. It may be augmented by personal or theologically based tendencies to avoid strong feelings or to respond to them repressively.

At the other extreme, there are some clergy who confuse counseling with insight psychotherapy and enter into ambitious and inappropriate therapeutic efforts. As a result of the recent enthusiasm for sensitivity training and encounter groups, certain clergy have become intensely involved in attempts at "self-awareness." Sometimes their enthusiasm is not tempered by a corresponding sense of the vulnerability of many people with personality difficulties and their needs for structure, control, and conventional social defenses. A few clergy in the community have left the active ministry and their greatest strengths - the religious tradition and the parish life-to become private, freestanding practitioners of pastoral counseling on the periphery of the mental health professions. We have generally been successful in avoiding this outcome in our program, perhaps because it helps clergy find a greater sense of fulfillment in their established ministry.

Unfortunately, the parish structure itself presents problems because of its incessant demands and the multiple roles that the pastor must fill. He may become caught in a crossfire in his efforts to function simultaneously as religious leader, personal counselor, organizational director, employer, employee, authority, role model, and ordinary human being with a personal life to live. Such emotional pressures are added to relentless demands upon his time, which make it hard for him to preserve a structured counseling situation. He may be unhappy with the compromises required to reconcile his varied roles.

At the same time that he is involved so extensively with this complex parish life, he may feel isolated from other clergy. Professional rivalries or the tensions of hierarchical structure may prevent him from turning to close associates or superiors for consultation and sharing of experiences. It may be difficult for him to admit inadequacy or disillusionment in his counseling efforts. He may confuse shortcomings of skill and technical knowledge with a failure in his religious vocation. The current questioning of religious beliefs may cause him to doubt the value or impact of his work. All of these factors make the minister, priest, or rabbi receptive to candid but confidential seminars with fellow clergy on ecumenical ground, under the auspices of mental health professionals who value his unique contributions.

Many psychiatrists, psychologists, and social workers who have not worked with the clergy express grave doubts that people working within the matrix of organized religion can be effective mental health resources. Regardless of our 
personal religious positions, our work with clergy enhanced our respect for the sincerity, integrity, and responsibility of the tradition in which they work. We have also come to recognize that many aspects of this tradition are supportive and therapeutic. We have learned that in many instances clergy must get involved in cases that do not reach the mental health establishment or that have exhausted its resources. We were impressed by the clergy's ability to learn from experience and to utilize intuitive common sense. Most of them seem to know their limitations; if anything, they underestimate their potential to be of help to their parishioners. They are also better able than we expected to sort out broad religious and philosophical issues from the practical, psychological aspects of a problem. As a group, they are bright, curious, and challenging students with a wealth of clinical experiences at their fingertips.

\section{Summary}

This paper presents observations on the assets and liabilities of the parish clergy as a mental health resource within the community. These observations are drawn from a ten-year program of continuing education for clergy in mental health, which focuses on daily pastoral experience. The parish setting is similar in many respects to the service area of a community mental health center. The clergy's assets often include availability, experience, tradition, and the special significance of the religious leader. Inadequate training in mental health skills and the complex demands of parish life are among the problems confronting the clergy in this area. On the whole, the pastoral role offers a unique and highly useful opportunity for positive psychological intervention.

\section{References}

1. Gurin, G., Veroff, J., and Feld, S., Americans View Their Mental Health, Report of the Joint Commission on Mental Illness and Health, No. 4. New York, Basic Books, 1960.

2. Caplan, R.B., Helping the Helpers to Help. New York, Seabury Press, 1972.

3. Westburg, G. E., and Draper, E., Community Psychiatry and the Clergyman. Springfield, Illinois, Charles C Thomas, 1966.

4. Wasman, M., Corradi, R., and Clemens, N., "A Continuing Education Program for Clergy in Mental Health Based Upon the Clinical Case Teaching Model." Submitted for publication.

5. Draper, E., Psychiatry and Pastoral Care. Englewood Cliffs, New Jersey, Prentice-Hall, 1965.

6. Farnsworth, D.L., and Braceland, F.J., Psychiatry, the Clergy and Pastoral Counseling. Collegeville, Minnesota, St. John's University Press, 1969.

7. Robertson, R.N., Maholick, L.T., and Shapiro, D.S., "The Parish Minister as Counselor: A Dilemma and Challenge," Pastoral Psychology, 1969, 20, 24-30.

8. Haugh, K.D., "Unique Contributions of Churches and Clergy to Community Mental Health," Community Ment. Health J., 1976, 12, 20-28.

9. Rosen, I., "Some Contributions of Religion to Mental and Physical Health," J. Religion and Health, 1974, 13, 289-294.

10. Clemens, N., "An Intensive Course for Clergy on Death, Dying, and Loss," J. Religion and Health, 1976, 15, 223-229. 